\title{
Mapping the prevalence and use of questionnaires to detect the neglected sexual side effects after prostate cancer treatment: a scoping review
}

\author{
Pierre Röscher ${ }^{1^{*}} \mathbb{D}$, Ronisha Sathiram² ${ }^{2}$ Joanne E. Milios ${ }^{3}$ and Jacqueline M. van Wyk ${ }^{4}$
}

\begin{abstract}
Background: Early prostate cancer (PCa) treatment interventions may leave men with debilitating sexual side effects, especially when not diagnosed or present at initial follow-up treatment. Men are often embarrassed to disclose their sexual dysfunction. This may lead to sexual side effects related to PCa treatment remaining untreated, adding to their burden of disability. This study was conducted to map the evidence on the prevalence of neglected sexual side effects (NSSE) after radical prostatectomy (RP) surgery or radiation treatment (RT) for PCa treatment and the reported use of questionnaires to identify such side effects.
\end{abstract}

Methods: This systematic scoping review's search strategy involved searching MEDLINE/PubMed, Science Direct and Google Scholar databases. Guided by eligibility criteria, two independent reviewers conducted title, abstract and fulltext screening. Data from the included studies were extracted. The review team explored the implications of the findings in relation to the research question and aims of the study. The Mixed Method Appraisal Tool was used to appraise the quality of the included studies. This review is reported according to the Preferred Reporting Items for Systematic Reviews and Meta-Analysis guidelines.

Results: Searches of the databases identified 1369 articles, with 23 eventually included for review. The prevalence of NSSE ranged between 0 and 78\% in studies reporting on early PCa treatment of RP and RT patients. Orgasmic dysfunction (5-78\%), penile curvature changes (10-15.9\%) and penile length shortening (0-55\%) similarly showed a low to moderate prevalence. Climacturia had low prevalence (4-5.2\%) after RT and moderate prevalence (21-38\%) after RP, whilst anejaculation had low to high prevalence (11-72\%) after RT. No validated questionnaire was used to detect any NSSE after early PCa treatment. Studies mainly modified other questionnaires, and two studies used non-validated questionnaires to identify some NSSE. Participants in the included studies reported being inadequately informed about the possible sexual side effects of their treatment.

Conclusion: This study showed a low to a high prevalence of NSSE in men after RP and RT for early PCa treatment. Questionnaires helped detect individual NSSEs after PCa treatment but there is currently no evidence of a valid, reliable and comprehensive questionnaire to detect the NSSE collectively.

Scoping review registration: N/A

*Correspondence: pierre.roscher@gmail.com

${ }^{1}$ Nelson R. Mandela School of Medicine, University of KwaZulu-Natal., 719

Umbilo Rd, Berea 4001 Umbilo, South Africa

Full list of author information is available at the end of the article

(c) The Author(s) 2021. Open Access This article is licensed under a Creative Commons Attribution 4.0 International License, which permits use, sharing, adaptation, distribution and reproduction in any medium or format, as long as you give appropriate credit to the original author(s) and the source, provide a link to the Creative Commons licence, and indicate if changes were made. The images or other third party material in this article are included in the article's Creative Commons licence, unless indicated otherwise in a credit line to the material. If material is not included in the article's Creative Commons licence and your intended use is not permitted by statutory regulation or exceeds the permitted use, you will need to obtain permission directly from the copyright holder. To view a copy of this licence, visit http://creativecommons.org/licenses/by/4.0/. The Creative Commons Public Domain Dedication waiver (http://creativeco mmons.org/publicdomain/zero/1.0/) applies to the data made available in this article, unless otherwise stated in a credit line to the data. 
Keywords: Prostate cancer, Prevalence, Questionnaire use, Neglected sexual side effects

\section{Background}

Prostate cancer (PCa) is a major cause of disease and morbidity amongst men, and it is the second most common cancer affecting men on a global scale [1]. Early PCa or localised PCa is cancer within the prostate described as stage I or II on the tumour-node-metastasis system [2]. Early PCa treatment consists of radical prostatectomy (RP) surgery or radiation therapy (RT), either offered through external beam radiotherapy or brachytherapy. The treatment may result in side effects such as sexual dysfunction [3] and less common physical deformities such as penile length shortening and penile curvature changes (Peyronie's disease) $[4,5]$. Sexual dysfunction from PCa treatment is common regardless of whether the treatment modality included surgical or non-surgical interventions. Sexual dysfunction is reported to increase during each year of followup after the initial intervention of RT, and it affects an average of $50 \%$ of patients within 5 years of receiving treatment [6].

Most men generally recover from pain and incontinence after RP but sexual side effects often remain untreated, leaving them with long-lasting and debilitating sexual dysfunction [7]. Men and their partners also suffer psychologically after PCa treatment due to anxiety and depression relating to sexual dysfunction [8]. Specific conditions related to physical, sexual dysfunction are common after PCa treatment. These conditions include orgasm-associated incontinence/ climacturia, urinary incontinence during sexual stimulation, altered perception of orgasm, pain with orgasm, anejaculation, penile length shortening, and penile deformity $[4,5,7,9]$. They are collectively referred to as the "neglected sexual side effects" (NSSE), and the symptoms are reportedly prevalent in $20-93 \%$ of RP patients [7].

Only a fifth of the men who have been diagnosed with PCa will ever discuss issues related to sexual dysfunction with their health care practitioners [10]. Clinicians may be able to use the responses from a specific patient questionnaire as a starting point to discussing issues relating to the patient's specific symptoms of sexual dysfunction. Two validated questionnaires, the Expanded Prostate Cancer Index Composite [11] and International Index of Erectile Function [12], were recommended for use in this context in 2015 [3]. Whilst the Expanded Prostate Cancer Index Composite and International Index of Erectile Function are available to stimulate the conversation around general urinary and sexual function, there is currently no validated instrument to identify the collective symptoms specific to NSSE after early PCa treatment $[4,5,13]$.

Two previous systematic reviews have explored and reported on the collective prevalence and assessment of NSSE [4, 7]. It has furthermore been established that there is no validated questionnaire to screen for NSSE and no evidence on the availability of a questionnaire to inquire about symptoms relating to NSSE in patients who had undergone treatment for PCa. It was, therefore, essential to map the evidence on the prevalence and use of questionnaires relating to the neglected sexual side effects after prostate cancer treatment to improve our understanding of NSSE and highlight knowledge gaps on the role of questionnaires in the assessment of the NSSEs.

\section{Methodology}

A protocol for this scoping review by Roscher and van Wyk [14] can be accessed at https://rdcu.be/b7i8I.

The scoping review followed the five steps described by Arksey and O' Malley [15] that included the following;

1. Identifying the research question

2. Identifying relevant studies

3. Study selection

4. Charting the data

5. Collating, summarising and reporting on the data

Quality assessment of each of the included primary studies was to be done as described by Levac et al. [16].

\section{Identifying the research questions}

The research was conducted to map the prevalence of NSSE and the use of a questionnaire to identify the NSSE after prostate cancer treatment. The research questions were as follows:

- What is the prevalence of the common NSSE's following early PCa treatment through surgical interventions/RP?

- What is the prevalence of the common NSSE following early PCa treatment through non-surgical interventions/RT?

- What are the role and use of questionnaires in detecting NSSE after early PCa treatment?

\section{Search strategy}

A literature search was conducted using the databases MEDLINE/PubMed, Science Direct and Google Scholar 
to search for articles matching the research questions. Boolean terms and MeSH (Medical Subject Heading) terms were employed using the keywords: Orgas* OR Pencil* OR Climacturia OR Dysorgasmia OR anejaculation OR Peyronie OR neglected AND (prostate cancer OR prostatectomy).

\section{Eligibility criteria}

The population, concept context (PCC) framework was used to determine the eligibility of studies for inclusion. The concept of interest was to identify studies on the prevalence of NSSE and the use of questionnaires to identify NSSE in a population of men after they had received surgical and non-surgical treatment following early PCa diagnosis.

The search was conducted on articles published between 1 January 2009 and 31 December 2019 only to include the most recent evidence on the use of questionnaires to identify NSSE. Other search parameters included original studies that were available in English and related to humans. Only studies that matched our aim in their titles were selected for further processing. The review excluded literature and grey literature outside the search period, unavailable in English and unrelated to sexual dysfunction.

\section{Study selection}

The identification of the relevant literature followed a systematic approach. The results of all three databases were combined into one Excel spreadsheet after applying the search parameters.

The primary reviewer performed the search strategy on the databases to retrieve publications and then removed all duplicates. The titles of studies were screened to determine their eligibility for inclusion. Two reviewers screened all retrieved abstracts and they were evaluated for eligibility using the inclusion criteria. Agreement between the reviewers about potentially relevant studies was reached, and the full text was obtained for screening. Two independent reviewers did the full-text screening, and a third investigator was engaged to resolve disagreements between reviewers.

\section{Charting the data}

A data charting form was developed to extract information on each publication and organise and synthesise information about each study (Additional file 1). The data collected included details on the author(s) and date of publication, the aim and research questions, the geographical context of the study, the population, study design and the number of participants. We also extracted information on the time reported since participants started the PCa treatment, the prevalence of NSSE and the reported use of questionnaires to identify NSSE after PCa.

The data sets were organised to answer each research question. Furthermore, the data relating to the prevalence of NSSE was organised according to the two main approaches for treating $\mathrm{PCa}$, those relating to surgical approaches (RP) and those following non-surgical approaches (RT).

\section{Quality appraisal}

An electronic version of the Mixed Method Appraisal Tool (MMAT) [17] was adapted to assess the quality of the included studies. The study designs included in this scoping review were qualitative, quantitative descriptive and mixed methods studies. The specific criteria to determine the appropriateness of each included study are outlined in Additional file 2.

Two reviewers independently performed the quality assessment, and the final scores were discussed for consensus. The overall quality for each included study was calculated according to the following MMAT guidelines $($ score $=$ number of criteria met/total score in each domain). One point was allocated when the study met each of the five criteria, and a total score in the form of a percentage represents the quality of the included studies (Additional file 2).

The results used the following descriptors.

- Very poor quality $(20 \%)$ where minimal criteria are met

- Poor quality $(40 \%)$ where less than half the criteria are not met

- Fair quality (60\%) where just more than half the criteria is met

- Good quality (80\%) where most of the criteria are being met

- Excellent quality (100\%) all criteria are met

The overall quality of a combination of components cannot be more than its weakest component in mixedmethods studies, making the overall score equal to the lowest-scoring component [17].

\section{Collating, summarising and reporting on the data}

The findings of this scoping review were analysed using a deductive content analysis approach, where themes were reported to answer each research question [18]. The review team discussed findings, resolved issues, and finalised findings. The review team explored the implications of the findings in how they relate to the study's aims and further research in the field.

The collected data was organised into subgroups (Additional file 1). The findings were analysed and reported 
according to the research questions. The data relating to the prevalence of the NSSE was quantitative, and the data about the use of a questionnaire yielded either one of 3 results: (i) a commonly used standardised questionnaire, (ii) an informal questionnaire, or (iii) no questionnaire. In addition to the methodologies mentioned above, the PRISMA-ScR checklist [19] guided the reporting of the scoping review (Additional file 3).

\section{Results}

A total of 1162 articles remained after removing the duplicates. After screening of titles, 66 articles remained, and 23 articles were found eligible and were included for full-text assessment after abstract screening. No additional studies were added after further consultation and screening of reference lists (Fig. 1).

Two studies were rated as being of excellent quality (100\% MMAT score), and the rest of the studies $(n=21)$ were rated as being of high quality (80\% MMAT score) (Additional file 2). As indicated in Table 1, the NSSE reported after RP were collectively reported 27 times, whereas NSSE's after RT were reported only 12 times.
Frey et al. published two studies in 2014 and 2017 that reported all 8 NSSEs of interest in our review. The 2017 study reported on NSSE following RT interventions, and the 2014 study reported on the prevalence of NSSE after $\mathrm{RP}$ interventions $[4,5]$.

All the studies included for review $(n=23)$ had crosssectional study designs and specifically examined NSSEs after PCa treatment. A summary is provided in Table 2. The included studies represented data from 9 countries, with 11 of the studies having been conducted in the USA. Eleven of the remaining studies were conducted in European countries; one study was conducted in South America (Brazil), and one was in Asia (Japan). No African or Australasian studies matched the inclusion criteria (see Fig. 2.)

\section{Orgasmic dysfunction/anorgasmia (7 studies)}

Six RP studies met the inclusion criteria [5, 20-24], whilst only one RT study reported on the prevalence of anorgasmia [4]. A low- to high prevalence range (5-78\%) was reported between studies for orgasmic dysfunction. Two thirds of men reported poor ability to orgasm at

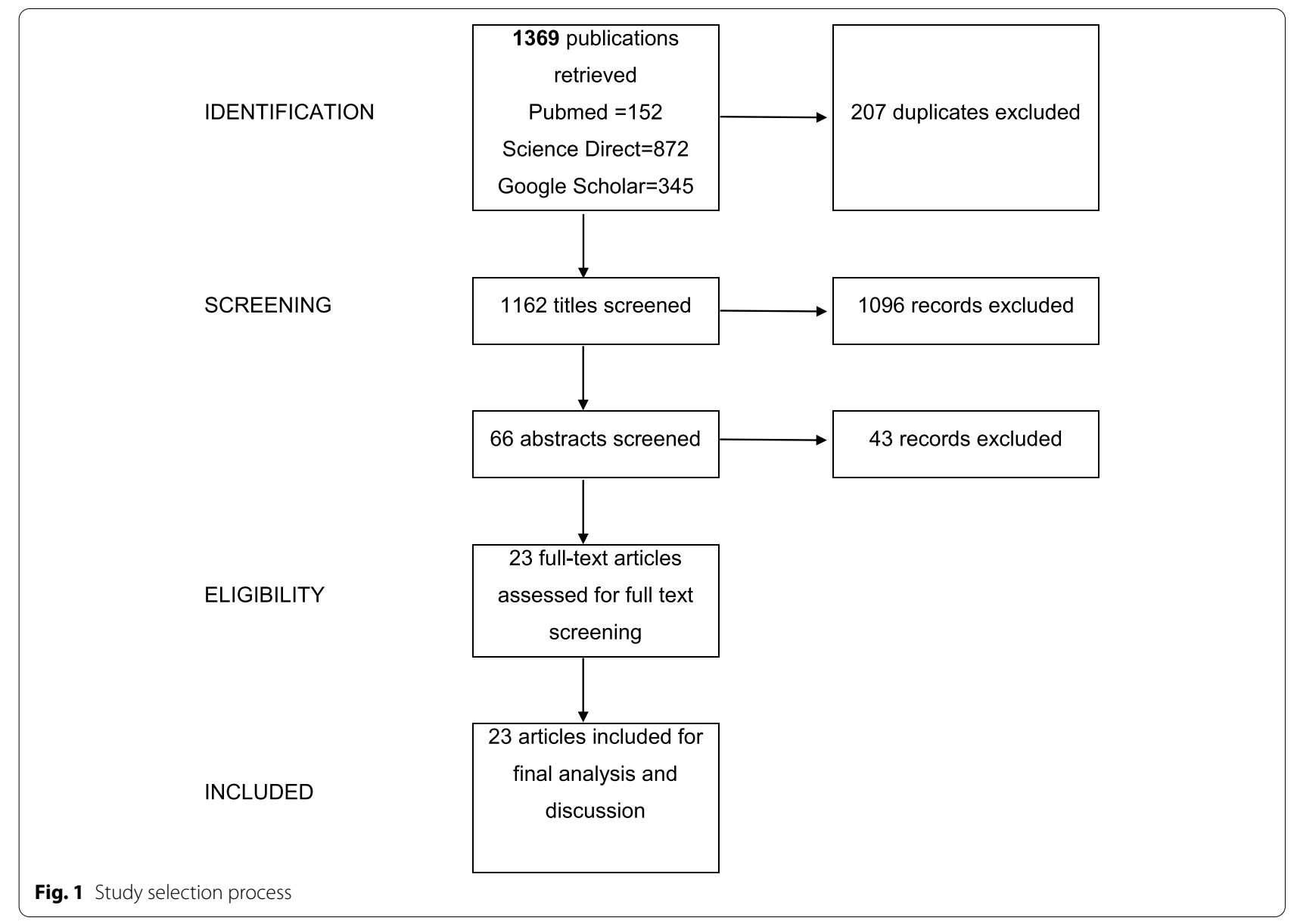


Table 1 Studies reporting of specific NSSE after PCa treatment

\begin{tabular}{|c|c|c|c|c|c|}
\hline \multicolumn{6}{|c|}{ NSSE after early PCa treatment after surgical and non-surgical intervention } \\
\hline & 27 studies & Surgical interventions (RP) & Non-surgical interventions ( $\mathrm{RT})$ & 12 studies & \\
\hline Reference & Number of studies & NSSE & & Number of studies & Reference \\
\hline$[5,20-24]$ & 6 & Orgasmic dysfunction & & 1 & {$[4]$} \\
\hline [5] & 1 & Altered perception of orgasm & & 1 & [4] \\
\hline$[5,24-26]$ & 4 & Orgasm-associated pain & & 1 & [4] \\
\hline \multirow[t]{2}{*}[5,27-30]{} & 5 & Climacturia & & 2 & {$[4,27]$} \\
\hline & 0 & Anejaculation & & 3 & {$[4,31,32]$} \\
\hline$[5]$ & 1 & Penile sensory changes & & 1 & {$[4]$} \\
\hline$[5,33-39]$ & 8 & Penile length shortening & & 2 & {$[4,36]$} \\
\hline$[5,40]$ & 2 & Penile deformity/Peyronie's disease & & 1 & {$[4]$} \\
\hline
\end{tabular}

3 years [20,21], and one third of men reported no orgasm at 2-5years after an RP [23, 24]. Orgasmic function improved postoperatively with time [24], also deteriorated with age [20, 22-24]. Nerve-sparing RP procedures predicted better post-operative orgasmic function [20, $22]$. Increased time needed to reach orgasm was experienced by almost half the men, 5 years after RT [4].

\section{Altered perception of orgasm (2 studies)}

One RP study [5] and one RT study [4] reported decreased orgasm intensity. Similar results were found in the RP study and the RT study. The RP study [5] showed that $60 \%$ of participants and almost $50 \%$ of the RT participants reported decreased orgasm intensity [4].

\section{Orgasm-associated pain/dysorgasmia (5 studies)}

Four studies included in this review reported on decreased orgasmic function after RP [5, 24-26] and one after RT [4]. Similar results were found between the RP studies, in that between 10 and $12 \%$ of RP participants reported orgasmic pain in RP $[5,25,26]$. The RT study reported a $15 \%$ prevalence of orgasmic pain in their study population [4].

\section{Orgasm-associated incontinence/climacturia (6 studies)}

Four RP studies met the inclusion criteria [5, 27-30], and one RT study was included for climacturia [4]. One study reported on both RP and RT participants [27]. The prevalence was reported between $21 \%$ [29] to 38\% [5] of participants across the five RP studies after 12-24 months (5, 27-30). The collaborative study recorded orgasm-associated incontinence/climacturia in $22.6 \%$ of the total study group (RP and RT participants), but the RT participants only represented $5.2 \%$ of the total participants [27]. The RT study reported a $4 \%$ prevalence of symptoms, but the symptoms were defined as urinary incontinence during sexual activity [4].

\section{Anejaculation (3 studies)}

No RP studies in the current review reported this issue, and three RT studies were included [4, 31, 32]. Anejaculation worsened with time after RT in one study and peaked at 5 years after treatment, with $89 \%$ of the study group being affected [32]. An older study reported a conflicting rate of anejaculation, with $81.3 \%$ of their participants conserving their ejaculatory function [31]. This study reported that $75 \%$ of the participants had a reduction in ejaculate volume and that $19 \%$ of the men experienced dry ejaculation [31]. The final study reported an anejaculation prevalence of $11 \%$ in their study population [4]

\section{Penile sensory changes ( 2 studies)}

Only one RP study [5] and one RT [4] study were included, with similar results being reported across the two studies. Penile sensory changes were reported in $25 \%$ of the RP study participants [5] and 27\% of the RT study participants [4].

\section{Penile length shortening (10 studies)}

Eight RP studies met the inclusion criteria for review [5, 33-39], and two RT studies [4, 36] studies were included for review. Only one study reported both on RT and RP and concluded that no RT participants had penile length shortening [36]. Penile length shortening was reportedly worse at $7-10$ days postoperatively $[33,34]$ but started recovering at 3-6 months [39]. However, self-perceived penile length shortening was still experienced by $55 \%$ of men two years after RP [37]. Men who eventually did not fully regain their penile length had experienced up to a $24 \%$ loss in length at 7 days postoperatively [33]. The second RT study reported that $42 \%$ of participants reported more than $1 \mathrm{~cm}$ subjective penile length shortening [4]. 
Table 2 Prevalence of NSSE

\begin{tabular}{|c|c|c|c|c|}
\hline NSSE reported & $\begin{array}{l}\text { First author/year/ } \\
\text { reference }\end{array}$ & Participant numbers/age & $\begin{array}{l}\text { Time frame after } \\
\text { intervention }\end{array}$ & $\begin{array}{l}\text { Reported prevalence in the } \\
\text { study population }\end{array}$ \\
\hline Multiple & Frey, 2017 [4] & 109 men (median age 71) & Three months to 5 years & $\begin{array}{l}24 \% \text { reported anorgasmia } \\
11 \% \text { reported anejaculation } \\
44 \% \text { reported a decrease in } \\
\text { orgasm intensity } \\
4 \% \text { reported urinary inconti- } \\
\text { nence during sexual activity } \\
40 \% \text { reported an increased } \\
\text { time needed to achieve } \\
\text { orgasm } \\
15 \% \text { reported pain during } \\
\text { orgasm } \\
27 \% \text { reported sensory } \\
\text { changes in their penis } \\
42 \% \text { reported penile length } \\
\text { shortening } \\
12 \% \text { reported an abnormal } \\
\text { curve in the penis }\end{array}$ \\
\hline Multiple & Frey, 2014 [5] & 316 men (median age 64) & 3-36 months & $\begin{array}{l}5 \% \text { of the sexually active } \\
\text { participants had reported } \\
\text { anorgasmia } \\
60 \% \text { of the sexually active } \\
\text { participants had reported a } \\
\text { decrease in orgasm intensity } \\
57 \% \text { reported delayed } \\
\text { orgasms } \\
10 \% \text { of sexually active partici- } \\
\text { pants had painful orgasms } \\
38 \% \text { reported urinary inconti- } \\
\text { nence during sexual activity } \\
25 \% \text { reported sensory } \\
\text { changes in their penis } \\
47 \% \text { reported a self-reported } \\
\text { penile length loss of more } \\
\text { than } 1 \mathrm{~cm} \\
10 \% \text { reported an abnormal } \\
\text { curve in the penis }\end{array}$ \\
\hline Orgasmic pain & Mogorovich, 2013 [25] & 1288 men (median age 63) & Six months to 5 years & $\begin{array}{l}11 \% \text { of participants reported } \\
\text { a painful orgasm in the previ- } \\
\text { ous } 6 \text { months }\end{array}$ \\
\hline Orgasmic pain & Matsushita, 2012 [26] & 702 men (mean age 64) & $6-24$ months & $\begin{array}{l}12 \% \text { of participants reported } \\
\text { dysorgasmia }\end{array}$ \\
\hline Orgasmic dysfunction & Du, 2017 [20] & 415 men (median age 60) & 36 months & $\begin{array}{l}60.2 \% \text { of participants had a } \\
\text { worse orgasmic function }\end{array}$ \\
\hline Orgasmic dysfunction & Ostby-Deglum, 2016 [21] & 609 men (median age 63) & Three years & $\begin{array}{l}78 \% \text { of participants had poor } \\
\text { ability to reach orgasm }\end{array}$ \\
\hline Orgasmic dysfunction & Tewari, 2012 [22] & 408 men (median age 60) & 36 months & $\begin{array}{l}11.6 \% \text { of participants under } \\
\text { age } 60 \text { unable to achieve } \\
\text { orgasm } / 17.4 \% \text { over } 60\end{array}$ \\
\hline Orgasmic dysfunction & Dubbelman, 2010 [23] & 458 men (median age 64) & Up to 2 years & $\begin{array}{l}33.2 \% \text { had orgasmic dysfunc- } \\
\text { tion afterwards with an age- } \\
\text { related decline }\end{array}$ \\
\hline $\begin{array}{l}\text { Orgasmic dysfunction }+ \\
\text { pain }\end{array}$ & Salonia, 2010 [24] & 334 men (median age 62) & Over 48 months & $\begin{array}{l}37 \% \text { of participants reported } \\
\text { complete inability to achieve } \\
\text { orgasm, } 14 \% \text { of participants } \\
\text { reported pain during orgasm }\end{array}$ \\
\hline OAl/climacturia & O'Neil, 2014 [27] & 412 men (mean age 62) & 10-20.3 months & $\begin{array}{l}\text { Climacturia was reported in } \\
22.6 \% \text { of the study group }\end{array}$ \\
\hline OAl/climacturia & Manassero, 2012 [28] & Seven men (mean age 64)) & One year & $\begin{array}{l}\text { 28.6\% Climacturia reported as } \\
\text { baseline investigations for a } \\
\text { N/A study }\end{array}$ \\
\hline
\end{tabular}


Table 2 (continued)

\begin{tabular}{|c|c|c|c|c|}
\hline NSSE reported & $\begin{array}{l}\text { First author/year/ } \\
\text { reference }\end{array}$ & Participant numbers/age & $\begin{array}{l}\text { Time frame after } \\
\text { intervention }\end{array}$ & $\begin{array}{l}\text { Reported prevalence in the } \\
\text { study population }\end{array}$ \\
\hline OAI/climacturia & Nilsson, 2011 [29] & 1261 men (median age 63) & Two years & $\begin{array}{l}21 \% \text { of the participants had } \\
\text { experienced orgasm-associ- } \\
\text { ated incontinence }\end{array}$ \\
\hline $\begin{array}{l}\text { Incontinence during sexual } \\
\text { activity }\end{array}$ & Mitchell, 2011 [30] & $\begin{array}{l}1421 \text { men (median age } \\
58,4)\end{array}$ & $3-24$ months & $\begin{array}{l}44 \% \text { and } 36.1 \% \text { at } 3 \text { months } \\
\text { and } 24 \text { months }\end{array}$ \\
\hline Ejaculation function & Sullivan, 2013 [32] & 364 men (median age 64) & Six years & $\begin{array}{l}72 \% \text { lost the ability to ejacu- } \\
\text { late in an anterograde fashion }\end{array}$ \\
\hline Ejaculatory function & Huyghe, 2009 [31] & 198 men (median age 65) & 36 months & $\begin{array}{l}18.7 \% \text { had impaired ejacula- } \\
\text { tory function }\end{array}$ \\
\hline Penile length shortening & Kwon, 2018 [33] & 507 men (median age 59,3) & Seven days to 12 months & $\begin{array}{l}60.2 \% \text { of the participants } \\
\text { regained their pre-op penile } \\
\text { length at } 12 \text { months }\end{array}$ \\
\hline Penile length shortening & Kadono, 2017 [34] & 102 men (median age 64,4) & Seven days to 24 months & $\begin{array}{l}\text { MRI results concluded } \\
\text { that the distal end of the } \\
\text { membranous urethra moved } \\
\text { proximally (mean proximal } \\
\text { displacement of } 3.9 \mathrm{~mm} \text { ) at } \\
10 \text { days after RP and then } \\
\text { returned to the preoperative } \\
\text { position at } 12 \text { months }\end{array}$ \\
\hline Penile length shortening & Berookhim, 2014 [35] & 118 Men (median age 58) & $\begin{array}{l}\text { Baseline, } 2 \text { months, } \\
6 \text { months }\end{array}$ & $\begin{array}{l}2.4 \mathrm{~mm} \text { difference (shorten- } \\
\text { ing) in stretched flaccid penis } \\
\text { length compared to baseline, } \\
\text { at } 6 \text { months, there was no dif- } \\
\text { ference compared to baseline }\end{array}$ \\
\hline Penile length shortening & Parekh, 2013 [36] & $\begin{array}{l}948(3 / 4 \text { of the participants }= \\
60-80 \text { years old })\end{array}$ & Unavailable & $\begin{array}{l}3.73 \% \text { of surgical cases } \\
\text { had reduced penile length } \\
\text { shortening, } \\
\text { O\% RT cases }\end{array}$ \\
\hline Penile length shortening & Carlson, 2012 [37] & $\begin{array}{l}1288 \text { men (median age } \\
64.8 \text { ) }\end{array}$ & 24.2 months & $\begin{array}{l}55 \% \text { of participants had } \\
\text { self-perceived penile length } \\
\text { shortening. }\end{array}$ \\
\hline Penile length shortening & Vasconcelos, 2012 [38] & 105 men (median age 65) & $3-60$ months & $\begin{array}{l}1 \mathrm{~cm} \text { mean penile length loss } \\
\text { at } 3 \text { to } 24 \text { months, baseline } \\
\text { penile length re-established } \\
\text { at } 48 \text { months }\end{array}$ \\
\hline Penile length shortening & Engel, 2011 [39] & 127 men (median age 56.5) & $1-11$ months after & $\begin{array}{l}11.77 \mathrm{~cm} \text { to } 11.13 \mathrm{~cm} \text { at } \\
1 \text { month after the surgery } \\
\text { Mean stretched penile length } \\
\text { was not significantly different } \\
\text { from baseline at } 9,10 \text { and } \\
11 \text { months }\end{array}$ \\
\hline $\begin{array}{l}\text { Penile length deformity/ } \\
\text { Peyronie's disease }\end{array}$ & Tal, $2010[40]$ & $\begin{array}{l}1011 \text { men (median age } \\
60.2 \text { ) }\end{array}$ & Up to 3 years & $\begin{array}{l}\text { Peyronie's disease incidence, } \\
15.9 \% \text { in RP population, } \\
\text { developed on average at } \\
13.9 \text { months, mean curvature } \\
\text { magnitude was } 31^{\circ}\end{array}$ \\
\hline
\end{tabular}

\section{Penile deformity/Peyronie's disease (3 studies)}

Two RP studies [5, 40] and one RT study [4] were included for review. Ten per cent of participants in a 2014 study were found to have an abnormal curvature of their penis [5]. Two studies on RP participants found that $10-15.9 \%$ of participants reported the presence of penile curvature or penile deformity $[5,40]$. The average reported curvature angle was $31^{\circ}$ [40]. A similar result was reported in the only RT study, where $12 \%$ of the participants reported an altered curve of the penis [4].

\section{Questionnaire use in NSSE studies}

The included studies used a variety of questionnaires that included validated and non-validated questionnaires. Some studies included a mixed-method design and added either an interview or a physical examination component 


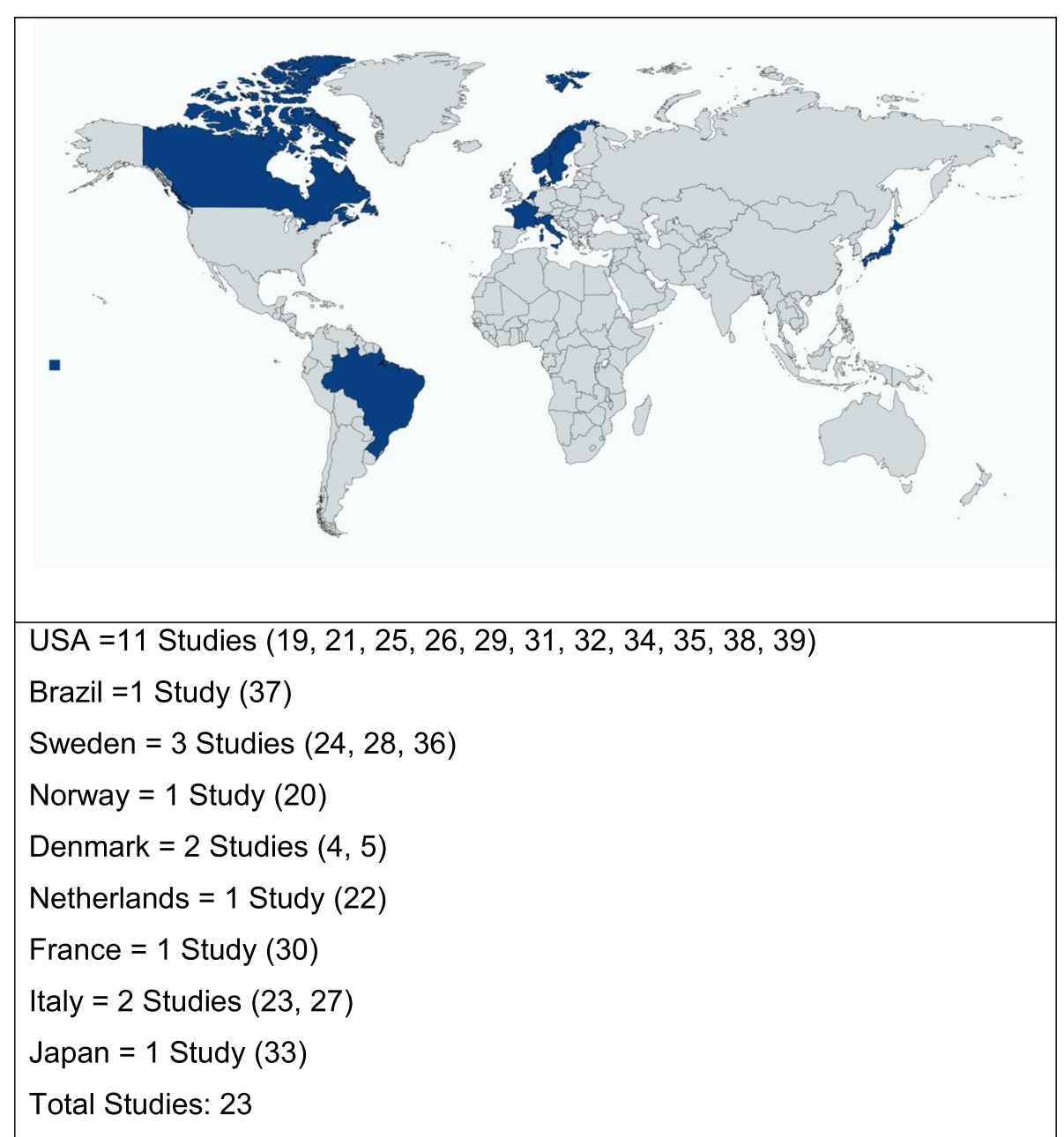

Fig. 2 Distribution of study origin

to the questionnaire. Table 3 outlines how questionnaires were used in the included studies.

\section{Discussion}

The NSSE after PCa treatment has gained some attention over the last few years. However, more attention is given to individual NSSE rather than the collective group, and more studies focus on the NSSE related to RP than RT. Comparisons across studies were limited as different methodologies, assessment time frames, varying treatment approaches, and the use of non-validated questionnaires varied and impacted the criteria for comparisons.

\section{Prevalence of NSSE}

Orgasmic dysfunction had a low to high prevalence. However, it was almost exclusively reported in RP studies (5-78\%), except for one RT study reporting a $24 \%$ prevalence amongst their participants [4]. Possible reasons for the considerable variation in the results across studies may be due to the variable lengths of time reported after the intervention, participant age, nerve sparing status and various methods/questionnaires to determine orgasmic dysfunction. This observation concurs with a 2014 systematic review where $80 \%$ of RP patients were reported to have some degree of orgasmic dysfunction after RP with similar variables influencing the prevalence [7].

Altered perception of orgasm showed a similar moderate prevalence (50-60\%) between RP and RT studies $[4,5]$. Orgasmic pain similarly showed a low prevalence (10-15\%) between RP and RT studies [4, 5, 25, 26, 41]. One study further described that the orgasmic pain felt mainly (70\% of the time) was felt in the penis [26]. At the same time, another made the association between bilateral seminal vesicle sparing procedures as a possible cause of orgasmic pain [25]. This notion was concurred in the systematic review by Frey et al., who reported that sparing the tips of the seminal vesicles doubles the risk of orgasmic pain [7]. 
Table 3 Questionnaire used after early PCa treatment

\begin{tabular}{|c|c|c|}
\hline NSSE reported & First author, year, reference & Questionnaire used to report NSSE \\
\hline Multiple & Frey, 2017 [4] & $\begin{array}{l}\text { Study-specific questionnaire based on various other questionnaires and } \\
\text { tools, including the Erection Hardness Scale and International Consulta- } \\
\text { tion of Incontinence-Short Form }\end{array}$ \\
\hline Multiple & Frey, $2014[5]$ & $\begin{array}{l}\text { Study-specific questionnaire based on various other questionnaires and } \\
\text { tools including the International Index of Erectile Function, International } \\
\text { Consultation of Incontinence-Short Form and Erection Hardiness Scale }\end{array}$ \\
\hline Orgasmic pain & Mogorovich, 2013 [25] & $\begin{array}{l}\text { Study-specific questionnaire consisting of } 145 \text { questions }-5 \text { pertaining } \\
\text { to orgasmic characteristics }\end{array}$ \\
\hline Orgasmic pain & Matsushita, 2012 [26] & Dysorgasmia Frequency Scale and Visual Analogue Scale \\
\hline Orgasmic dysfunction & Du et, 2017 [20] & $\begin{array}{l}\text { Expanded Prostate Index Composite, American Urological Association } \\
\text { Symptom Index and Sexual Health Inventory for Men. Participants were } \\
\text { asked to rate their post-operative orgasmic function }\end{array}$ \\
\hline Orgasmic dysfunction & Ostby-Deglum, 2016 [21] & Expanded Prostate Index Composite 26_one single question asked \\
\hline Orgasmic dysfunction & Tewari, $2012[22]$ & $\begin{array}{l}\text { Health-Related Quality of Life questionnaire, Expanded Prostate Index } \\
\text { Composite and International Index of Erectile Function. Participants were } \\
\text { asked to rate their post-operative orgasmic function }\end{array}$ \\
\hline Orgasmic dysfunction & Dubbelman, 2010 [23] & N/A \\
\hline Orgasmic dysfunction & Salonia, 2010 [24] & $\begin{array}{l}\text { International Index of Erectile Function and International Consultation of } \\
\text { Incontinence -Short Form. Structured Interviews }\end{array}$ \\
\hline Orgasm-associated incontinence/climacturia & O’Neil, 2014 [27] & A non-validated questionnaire was used \\
\hline Orgasm-associated incontinence/climacturia & Manassero, 2012 [28] & $\begin{array}{l}\text { International Index of Erectile Function ( } 5 \text { Item) and International } \\
\text { Prostate Symptom Score. Telephonic interview about orgasm-associated } \\
\text { incontinence/climacturia }\end{array}$ \\
\hline Orgasm-associated urinary incontinence & Nilsson, 2011 [29] & $\begin{array}{l}\text { The author designed a study-specific questionnaire based on the Scandi- } \\
\text { navian prostate cancer group } 4 \text { questionnaire. }\end{array}$ \\
\hline Incontinence during sexual activity & Mitchell, 2011 [30] & The University of California and Los Angeles Prostate Cancer Index. \\
\hline Ejaculation function & Sullivan, 2013 [32] & International Index of Erectile Dysfunction \\
\hline Ejaculatory function & Huyghe, 2009 [31] & $\begin{array}{l}\text { The author designed a study-specific questionnaire based on an adapted } \\
\text { Male Sexual Health questionnaire }\end{array}$ \\
\hline Penile length shortening & Kwon, 2018 [33] & Sexual Health Inventory for Men and Physical measurement \\
\hline Penile length shortening & Kadono, 2017 [34] & $\begin{array}{l}\text { International Index of Erectile Function and Erection Hardness Score. The } \\
\text { physical exam using a ruler to measure stretched flaccid penile length }\end{array}$ \\
\hline Penile length shortening & Berookhim, 2014 [35] & $\begin{array}{l}\text { International Index of Erectile Function questionnaire. Physical exam to } \\
\text { measure stretched flaccid penile length }\end{array}$ \\
\hline Penile length shortening & Parekh, 2013 [36] & A non-validated questionnaire was used \\
\hline Penile length shortening & Carlsson, 2012 [37] & $\begin{array}{l}\text { The author designed a study-specific questionnaire based on previous } \\
\text { work of the study group }\end{array}$ \\
\hline Penile length Shortening & Vasconcelos, 2012 [38] & International Index of Erectile Function. Physical Assessment \\
\hline Penile length shortening & Engel, 2011 [39] & $\begin{array}{l}\text { International Index of Erectile Function. The physical exam using a semi- } \\
\text { rigid ruler to measure stretched flaccid penile length }\end{array}$ \\
\hline Peyronie's disease & Tal, $2010[40]$ & Descriptive statistics. Physical examination with a goniometer \\
\hline
\end{tabular}

Penile length changes showed a low to moderate prevalence (0-55\%) after RP and RT [4, 5, 33-39]. Nerve-sparing procedures reportedly reduced the risk of self-perceived penile length shortening [37], whilst younger age and better preoperative erectile function were associated with complete penile length recovery [33]. Penile length shortening was also associated with treatment regret [36]. Furthermore, the self-perceived penile length shortening was found to be much more than actual penile length shortening measured using a ruler [37]. The study by Parekh et al. is of particular interest as an outlier study, as they only reported a $3.73 \%$ $\mathrm{RP}$ and a $0 \% \mathrm{RT}$ prevalence of penile length shortening [36]. This study relied on self-reported patient outcomes, but participants were not instructed on the required measuring procedures (stretched or relaxed flaccid penile length or erect penile length). Furthermore, the majority of the participants $(75.4 \%)$ in Park et al's study were aged between 60 and 80 years old. The lack of available baseline data compromised the ability to determine penile length loss objectively. Frey et al. reported a 15-68\% prevalence of penile length shortening in their study [7], 
placing the results of a $42 \%$ (RT study) [4] and $47 \%$ (RP study) [5] more within the expected range.

Penile curvature changes were also similar between RP and RT studies, showing a low prevalence (10-15.9\%) [4, $5,40]$, and the average reported abnormal penile curvature angle was $31^{\circ}$ [40]. Penile sensory changes showed an almost similar moderate prevalence between RP (25\%) and RT (27\%) participants [4, 5].

Anejaculation was found to have a low to high prevalence (11-72\%) after RT [4, 31, 32]. According to this review, anejaculation is a consequence of RT [31, 32], and it is at its worst 5 years after treatment [32]. Conserved ejaculatory function is often associated with a reduction in ejaculate volume. Higher RT dose, older age and smaller prostates at the time of treatment increased the likelihood of failure to ejaculate [32]. Anejaculation is, however, also a given consequence of RP, as the ejaculatory apparatus (prostate, seminal vesicles and ejaculatory ducts) are removed [7, 42]. However, the authors could not source any studies within our search parameters that met the study inclusion criteria.

Climacturia has a reported moderate prevalence (21$38 \%)$ after RP $[5,27-30]$ and a low prevalence (4-5.2\%) after RT $[4,27]$. A comparative study concluded that the orgasm-associated incontinence rates after RP were six times more than that of RT (28.3\% vs 5.2\%) [27]. Climacturia is associated with major sexual inconvenience and bother [29].

\section{Questionnaire used in assessing NSSE}

None of the retrieved studies reported on a validated, standardised questionnaire to investigate the NSSE after early PCa treatment. Most studies incorporated either some aspects of other questionnaires or designed their own. Two studies used a non-validated questionnaire that was able to identify the majority of the collective group of NSSE $[4,5]$. This questionnaire enquired about orgasmic dysfunction, orgasm-associated pain, climacturia, penile sensory changes, penile length shortening and penile deformity. These two studies looked mainly and the prevalence and predicting factors of the NSSE.

Interestingly, a limited number of studies reportedly described the use of the Expanded Prostate Cancer Index questionnaire [11] to gather patient data relating to orgasmic dysfunction [20-22]. However, the Expanded Prostate Cancer Index questionnaire was inadequate to report on the NSSE, and additional questions that inquired into orgasmic function were added [20, 22]. The Expanded Prostate Cancer Index-26 questionnaire was similarly inadequate to detect NSSE. It merely asked respondents to "rate their ability to reach orgasm" without exploring any symptoms relating to the other NSSE [21].
A 2011 study used the Expanded Prostate Cancer Index questionnaire similarly at regular intervals after surgery to investigate orgasmic outcomes [22]. In addition, patients were asked to evaluate their orgasm and state whether they experienced any pain during orgasms. One study also incorporated the Dysorgasmia Frequency Scale [26]. The International Index Erectile Function was used in many studies [5, 22, 24, 28, 32, 34, 35, 38, 39] but served no purpose in detecting any of the NSSE. The Erection Hardness Scale [43] was used in a few studies $[5,34]$ and had no role in detecting the NSSE. The Sexual Health Inventory for Men questionnaire (a modified 5 -item version of the International Index Erectile Function) was used in two studies [20,33], and another study [31] based their informal questionnaire on the Male Sexual Health Questionnaire [44].

Orgasm-associated incontinence/climacturia was further assessed by a non-validated author designed questionnaire [27] and a study-specific questionnaire based on the Scandinavian Prostate Cancer Group 4 questionnaire [29] in two separate studies. A telephonic interview was added to a non-NSSE questionnaire to probe the presence of climacturia in a 2012 study [28].

Anejaculation was assessed in a study that used the International Index of Erectile Function questionnaire [32]. A sexual medicine physician initially interviewed the participants. They were then questioned about their ejaculatory function (presence/absence, intensity and ease of achievement) and orgasm (presence/absence, intensity and ease of achievement). Only those who were sexually active were asked to complete the questionnaire. Questions 9 and 10 respectively asked: "When you had sexual stimulation or intercourse, how often did you ejaculate?" and "When you had sexual stimulation or intercourse, how often did you have the feeling of orgasm or climax?" [32]. A 2009 study used a modified version (5 items, not 7) of the Male Sexual Health questionnaire that specifically addressed: (i) frequency, (ii) volume, (iii) dryness, (iv) pleasure and (v) pain during ejaculation [31].

Penile length shortening was assessed in a 2012 study using an author designed questionnaire containing questions relating to self-perceived penile length shortening [37]. Penile length shortening and penile deformity/ Peyronie's disease were not assessed by any other questionnaires apart from the collective NSSE questionnaire mentioned $[4,5]$, but rather through physical examinations. Three studies used a semi-rigid ruler for a physical penile length examination [34, 35, 39]. Vasconcelos et al. used an anthropometric ruler as a physical measurement to assess shortening [38]. Parekh et al. reported in their study that physicians completed a questionnaire based on their patients, and one question includes under "the 
complaints section" referred to reduced penile length [36].

Penile deformity was assessed in one additional study by Tal et al., where they assessed a penile curvature with a goniometer if the patient reported an abnormal curvature [40].

\section{Strengths and limitations of the study}

The methodology used and the search period used allowed for the systematic and extensive literature search, which sought to map only the most recent developments on the prevalence of NSSE and the use of questionnaires to identify NSSE. Additionally, the scoping review results were presented following the PRISMA recommendations, which ensured complete and transparent reporting. The MMAT tool version 2011 was used to assess the methodological quality of the included studies.

Limitations of this study included the fact that the studies included variables that were not consistent between studies. The reader should be cautioned when interpreting the results of the prevalence indicators for different NSSEs.

Furthermore, only original research was included, and other sources of information could have further clarified some discrepancies in the results.

\section{Conclusion}

This study found a low to a high prevalence of NSSE reported in men after RP and RT. Penile deformity, orgasmic dysfunction, and penile length shortening were low to moderately prevalent, similar to RP and RT. Anejaculation prevalence was low to high after RT. Climacturia was shown to have a low prevalence after RT and a moderate prevalence after RP (six times more than RT). A common theme through most of the studies was that the participants expressed not being adequately informed about the possible sexual side effects before commencing their PCa treatment. Questionnaires effectively assess sexual dysfunction, and many modified informal non-specific questionnaires are used to detect conditions related to sexual dysfunction. There is currently no valid and reliable questionnaire to detect the collective NSSE after PCa treatment. There is a need to develop a validated and reliable NSSE questionnaire for use after PCa treatment for quick and effective diagnosis.

\section{Abbreviations}

PCa: Prostate cancer; NSSE: Neglected sexual side effects; PCC: Population concept context; MeSH: Medical Subject Heading; MMAT: Mixed Method Appraisal Tool; PRISMA-ScR: Preferred Reporting Items for Systematic Reviews and Meta-Analysis Extension for Scoping Reviews; RP: Radical prostatectomy; RT: Radiation therapy.

\section{Supplementary Information}

The online version contains supplementary material available at https://doi. org/10.1186/s13643-021-01865-5.

Additional file 1. Collected data organised into subgroups.

Additional file 2. The specific criteria to determine the appropriateness of each included study.

Additional file 3. Preferred Reporting Items for Systematic reviews and Meta-Analyses extension for Scoping Reviews (PRISMA-ScR) Checklist.

\section{Acknowledgements}

None

\section{Authors' contributions}

PR conceived the study and participated in the design involved in drafting and finalising the manuscript. RS revised the manuscript and provided clinical input and approved the manuscript for final submission. JM came up with the study idea, provided clinical input and revised the manuscript for final submission. JvW participated in the conceptual design of the study, drafting the manuscript and revising it critically, providing final approval of the version to be published. The authors read and approved the final manuscript.

\section{Authors' information}

Pierre Röscher: Currently a PhD student in the discipline of Urology at Nelson R Mandela School of Medicine, University of KwaZulu Natal, South Africa

Dr Ronisha Sathiram is a urologist and department head of Urology at Greys in Pietermaritzburg Hospital. She is a lecturer and an affiliate to the Nelson R Mandela School of Medicine, University of KwaZulu Natal, South Africa Dr Joanne Milios is a men's health physiotherapist and clinical researcher affiliated with the School of Sport Science, Exercise \& Health, the University of Western Australia.

Prof. Jacqueline van Wyk is an associate professor at the Nelson R Mandela School of Medicine, University of KwaZulu Natal, South Africa.

Funding

Not applicable

Availability of data and materials

Not applicable

\section{Declarations}

Ethics approval and consent to participate

Full ethical clearance was obtained from the University of KwaZulu-Natal, School of Health Sciences Research Committee (Biomedical Research Ethics Committee) with registration no: BREC/00000478/2019.

\section{Consent for publication}

Not applicable

Competing interests

The authors declare that they have no competing interests.

\section{Author details}

${ }^{1}$ Nelson R. Mandela School of Medicine, University of KwaZulu-Natal, 719 Umbilo Rd, Berea 4001 Umbilo, South Africa. ${ }^{2}$ Greys Hospital Pietermaritzburg, and Clinical Researcher and Professional Practice Nelson R. Mandela School of Medicine, University of KwaZulu-Natal., 719 Umbilo Rd, Berea 4001 Umbilo, South Africa. ${ }^{3}$ School of Sport Science, Exercise \& Health, The University of Western Australia., Parkway Rd, 6009 Crawley, Western Australia. ${ }^{4}$ Nelson R. Mandela School of Medicine, University of KwaZulu-Natal., 719 Umbilo Rd, Berea 4001 Umbilo, South Africa. 
Received: 9 June 2020 Accepted: 2 December 2021

Published online: 03 January 2022

\section{References}

1. Rawla P. Epidemiology of prostate cancer. World J Oncol. 2019;10(2):63-89.

2. Buyyounouski MK, Choyke PL, McKenney JK, Sartor O, Sandler HM, Amin $\mathrm{MB}$, et al. Prostate cancer - major changes in the American Joint Committee on Cancer eighth edition cancer staging manual. CA Cancer J Clin. 2017;67(3):245-53

3. Salonia A, Adaikan G, Buvat J, Carrier S, El-Meliegy A, Hatzimouratidis K, et al. Sexual rehabilitation after treatment for prostate cancer-part 1: recommendations from the fourth International Consultation for Sexual Medicine (ICSM 2015). J Sexual Med. 2017;14(3):285-96.

4. Frey A, Pedersen C, Lindberg H, Bisbjerg R, Sonksen J, Fode M. Prevalence and predicting factors for commonly neglected sexual side effects to externalbeam radiation therapy for prostate cancer. J Sexual Med. 2017;14(4):558-65.

5. Frey AS, J. Jakobsen, H.: Fode, M. Prevalence and predicting factors for commonly neglected sexual side effects to radical prostatectomies: results from a cross-sectional questionnaire-based study. J Sexual Med. 2014;11(9):2318-26.

6. Gaither TW, Awad MA, Osterberg EC, Murphy GP, Allen IE, Chang A, et al. The natural history of erectile dysfunction after prostatic radiotherapy: a systematic review and meta-analysis. J Sexual Med. 2017;14(9):1071-8.

7. Frey AU, Sonksen J, Fode M. Neglected side effects after radical prostatectomy: a systematic review. J Sexual Med. 2014;11(2):374-85.

8. Albaugh JA, Sufrin N, Lapin BR, Petkewicz J, Tenfelde S. Life after prostate cancer treatment: a mixed methods study of the experiences of men with sexual dysfunction and their partners. BMC Urol. 2017;17(1):45.

9. Salonia A, Adaikan G, Buvat J, Carrier S, El-Meliegy A, Hatzimouratidis K, et al. Sexual rehabilitation after treatment for prostate cancer-part 2: recommendations from the fourth International Consultation for Sexual Medicine (ICSM 2015). J Sexual Med. 2017;14(3):297-315.

10. Ben Charif A, Bouhnik AD, Courbiere B, Rey D, Preau M, Bendiane MK, et al. Patient discussion about sexual health with health care providers after cancer-a national survey. J Sexual Med. 2016;13(11):1686-94.

11. Szymanski KM, Wei JT, Dunn RL, Sanda MG. Development and validation of an abbreviated version of the expanded prostate cancer index composite instrument for measuring health-related quality of life among prostate cancer survivors. Urology. 2010;76(5):1245-50.

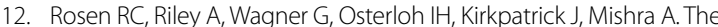
international index of erectile function (IIEF): a multidimensional scale for assessment of erectile dysfunction. Urology. 1997:49(6):822-30.

13. Nolsøe AB, Jensen CFS, Østergren PB, Fode M. Neglected side effects to curative prostate cancer treatments. Int J Impot Res. 2021:33(4):428-38.

14. Roscher P, van Wyk JM. Mapping the prevalence of the neglected sexual side effects after prostate cancer treatment and the questionnaires used in their screening: a scoping review protocol. Syst Rev. 2020;9(1):214.

15. Arksey HOM, L. Scoping studies:towards a methodological framework. Int J Soc Res Methodol. 2005:8(1):19-32.

16. Levac D, Colquhoun H, O'Brien KK. Scoping studies: advancing the methodology. Implement Sci. 2010;5:69.

17. Hong QNbF, Sergic |Bartlett, Gilliana | Boardman, Felicityd | Cargo, Margarete | Dagenais, Pierref | Gagnon, Marie-Pierreg | Griffiths, Francesd | Nicolau, Belindah | O'Cathain, Aliciai | Rousseau, Marie-Claudej |Vedel, Isabellea | Pluye, Pierrea; $b$; * The Mixed Methods Appraisal Tool (MMAT) version 2018 for information professionals and researchers. Educ Information. 2018;34(4):285-291.

18. Elo S, Kyngas $\mathrm{H}$. The qualitative content analysis process. J Adv Nurs. 2008;62(1):107-15.

19. Tricco AC, Lillie E, Zarin W, O'Brien KK, Colquhoun H, Levac D, et al. PRISMA Extension for Scoping Reviews (PRISMA-ScR): Checklist and Explanation. Ann Intern Med. 2018;169(7):467-73.

20. Du K, Zhang C, Presson AP, Tward JD, Brant WO, Dechet CB. Orgasmic function after radical prostatectomy. J Urol. 2017;198(2):407-13.

21. Ostby-Deglum M, Axcrona K, Brennhovd B, Dahl AA. Ability to reach orgasm in patients with prostate cancer treated with robot-assisted laparoscopic prostatectomy. Urology. 2016;92:38-43.

22. Tewari A, Grover S, Sooriakumaran P, Srivastava A, Rao S, Gupta A, et al. Nerve sparing can preserve orgasmic function in most men after robotic-assisted laparoscopic radical prostatectomy. BJU Int. 2012;109(4):596-602.
23. Dubbelman Y, Wildhagen M, Schroder F, Bangma C, Dohle G. Orgasmic dysfunction after open radical prostatectomy: clinical correlates and prognostic factors. J Sexual Med. 2010;7(3):1216-23.

24. Salonia A, Gallina A, Briganti A, Colombo R, Bertini R, Da Pozzo LF, et al. Postoperative orgasmic function increases over time in patients undergoing nerve-sparing radical prostatectomy. J Sexual Med. 2010;7(1 Pt 1):149-55.

25. Mogorovich A, Nilsson AE, Tyritzis SI, Carlsson S, Jonsson M, Haendler L, et al. Radical prostatectomy, sparing of the seminal vesicles, and painful orgasm. J Sexual Med. 2013:10(5):1417-23.

26. Matsushita K, Tal R, Mulhall JP. The evolution of orgasmic pain (dysorgasmia) following radical prostatectomy. J Sexual Med. 2012;9(5):1454-8.

27. O'Neil BB, Presson A, Gannon J, Stephenson RA, Lowrance W, Dechet CB, et al. Climacturia after definitive treatment of prostate cancer. J Urol. 2014;191(1):159-63.

28. Manassero F, Di Paola G, Paperini D, Mogorovich A, Pistolesi D, Valent F, et al. Orgasm-associated incontinence (climacturia) after bladder neck-sparing radical prostatectomy: clinical and video-urodynamic evaluation. J Sexual Med. 2012;9(8):2150-6

29. Nilsson AE, Carlsson S, Johansson E, Jonsson MN, Adding C, Nyberg T, et al. Orgasm-associated urinary incontinence and sexual life after radical prostatectomy. J Sexual Med. 2011:8(9):2632-9.

30. Mitchell SA, Jain RK, Laze J, Lepor H. Post-prostatectomy incontinence during sexual activity: a single center prevalence study. J Urol. 2011;186(3):982-5.

31. Huyghe E, Delannes M, Wagner F, Delaunay B, Nohra J, Thoulouzan M, et al. Ejaculatory function after permanent 125 I prostate brachytherapy for localized prostate cancer. Int J Radiation Oncol Biol Physics. 2009;74(1):126-32.

32. Sullivan JF, Stember DS, Deveci S, Akin-Olugbade Y, Mulhall JP. Ejaculation profiles of men following radiation therapy for prostate cancer. J Sexual Med. 2013;10(5):1410-6

33. Kwon YS, Farber N, Yu JW, Rhee K, Han C, Ney P, Kim IY. Longitudinal recovery patternsof penile length and the underexplored benefit of long-term phosphodiesterase-5 inhibitor use after radical prostatectomy. BMC Urology. 2018;18(1):1-8.

34. Kadono Y, Machioka K, Nakashima K, lijima M, Shigehara K, Nohara T, et al. Changes in penile length after radical prostatectomy: investigation of the underlying anatomical mechanism. BJU International. 2017;120(2):293-9.

35. Berookhim BM, Nelson CJ, Kunzel B, Mulhall JP, Narus JB. Prospective analysis of penile length changes after radical prostatectomy. BJU Int. 2014:113(5b):E131-6.

36. Parekh A, Chen M-H, Hoffman KE, Choueiri TK, Hu JC, Bennett CL, et al. Reduced penile size and treatment regret in men with recurrent prostate cancer after surgery, radiotherapy plus androgen deprivation, or radiotherapy alone. Urology. 2013:81(1):130-5.

37. Carlsson S, Nilsson AE, Johansson E, Nyberg T, Akre O, Steineck G. Self-perceived penile shortening after radical prostatectomy. Int J Impot Res. 2012;24(5):179-84.

38. Vasconcelos JS, Figueiredo RT, Nascimento FL, Damiao R, da Silva EA. The natural history of penile length after radical prostatectomy: a long-term prospective study. Urology. 2012;80(6):1293-6.

39. Engel JD, Sutherland DE, Williams SB, Wagner KR. Changes in penile length after robot-assisted laparoscopic radical prostatectomy. J Endourol. 2011;25(1):65-9.

40. Tal R, Heck M, Teloken P, Siegrist T, Nelson CJ, Mulhall JP. Original researchPeyronie's disease: Peyronie's disease following radical prostatectomy: incidence and predictors. J Sexual Med. 2010;7(3):1254-61.

41. Frey A, Sonksen J, Jakobsen H, Fode M. Prevalence and predicting factors for commonly neglected sexual side effects to radical prostatectomies: results from a cross-sectional questionnaire-based study. J Sexual Med. 2014;11(9):2318-26.

42. Salonia A, Burnett AL, Graefen M, Hatzimouratidis K, Montorsi F, Mulhall JP, et al. Prevention and management of postprostatectomy sexual dysfunctions part 2: recovery and preservation of erectile function, sexual desire, and orgasmic function. Eur Urol. 2012;62(2):273-86.

43. Mulhall JP, Goldstein I, Bushmakin AG, Cappelleri JC, Hvidsten K. Original research-outcomes assessment: validation of the Erection Hardness Score J Sexual Med. 2007:4(6):1626-34.

44. Rosen RC, Catania J, Pollack L, Althof S, O'Leary M, Seftel AD. Male Sexual Health Questionnaire (MSHQ): scale development and psychometric validation. Urology. 2004:64(4):777-82.

\section{Publisher's Note}

Springer Nature remains neutral with regard to jurisdictional claims in published maps and institutional affiliations. 